\begin{tabular}{l} 
SCIENCE \& TECHNOLOGY \\
Journal homepage: http://www.pertanika.upm.edu.my/ \\
\hline PERTANIKA
\end{tabular}

\title{
Esterification of Free Fatty Acid in Palm Oil Mill Effluent using Sulfated Carbon-Zeolite Composite Catalyst
}

\author{
Hasanudin Hasanudin ${ }^{*}$, Qodria Utami Putri', Tuty Emilia Agustina ${ }^{2}$ and \\ Fitri Hadiah ${ }^{2}$ \\ ${ }^{1}$ Department of Chemistry, Universitas Sriwijaya, Palembang, 30662 Indonesia \\ ${ }^{2}$ Department of Chemical Engineering, Universitas Sriwijaya, Palembang, 30662 Indonesia
}

\begin{abstract}
Free fatty acid esterification (FFA) in palm oil mill effluent (POME) was carried out using a sulfonated carbon-zeolite composite catalyst. The catalyst is synthesized with carbon precursor obtained from molasses, which is adsorbed on the surface of the zeolite and then carbonized and sulfonated with concentrated $\mathrm{H}_{2} \mathrm{SO}_{4}$ to form a sulfonated carbon-zeolite catalyst composite, which will be used for the esterification catalyst and the optimization process for the esterification reaction is carried out using the response surface methodology (RSM) and experimental central composite design (CCD). Importantly, the observed independent variables were temperature, catalyst weight, and reaction time to produce fatty acid methyl ester (FAME) products. The catalyst was successfully synthesized, which was shown from the SEM characterization strengthened by the presence of a sulfate group in the FTIR results and the calculation results of high acidity properties. Optimization of FFA esterification with SCZ catalyst obtained optimal conditions with a temperature of $79^{\circ} \mathrm{C}$, a catalyst weight of $3.00 \mathrm{~g}$, and a reaction time of 134 minutes with a FAME product of $93.75 \%$, considering that the viscosity of biodiesel is below that required by the API.
\end{abstract}

Keywords: Biodiesel, esterification, palm oil mill effluent, sulfonated carbon

ARTICLE INFO

Article history:

Received: 12 May 2021

Accepted: 15 September 2021

Published: 04 Januari 2022

DOI: https://doi.org/10.47836/pjst.30.1.21

$\overline{\text { E-mail addresses: }}$

Hasanudin@mipa.unsri.ac.id; Hasanudinkf@gmail.com

(Hasanudin Hasanudin)

qodriaria@gmail.com (Qodria Utami Putri)

tuty_agustina@unsri.ac.id (Tuty Emilia Agustina)

fitrihadiah@ft.unsri.ac.id (Fitri Hadiah)

* Corresponding author

\section{INTRODUCTION}

The crude palm oil (CPO) industry generates a large quantity of liquid waste in the form of POME, available in large quantities with a high content FFA (Hasanudin et al., 2012). It has the potential to be converted to biodiesel through esterification with alcohol. However, the high FFA in POME cannot be processed using a base catalyst 
since it reacts to produce soap and might complicate the process of separating esters from glycerol (Aboelazayem et al., 2019; de Jesus et al., 2018). To solve this problem, some researchers use homogeneous acid catalysts for the production of biodiesel derived from ingredients with high FFA content (Encinar et al., 2011; Gebremariam \& Marchetti, 2018a). The homogeneous catalysts, such as acids and alkaline homogeneous, can be used in free fatty acid esterification reactions like $\mathrm{KOH}, \mathrm{NaOH}$, and $\mathrm{H}_{2} \mathrm{SO}_{4}$ (Borugadda \& Goud, 2012). However, these alternatives have many drawbacks, such as being economically inefficient, resulting in corrosion of equipment and reactors as well as damaging machinery (Gebremariam \& Marchetti, 2018b; Marchetti et al., 2008; Encinar et al., 2011).

Homogeneous acid catalysts can be modified into solid acid catalysts. For example, although the sulfuric acid catalyst is a homogeneous catalyst commonly used to catalyze esterification reactions, sulfuric acid catalysts can also be applied to solids, such as carbon (Mardhiah et al., 2017; Lathiya et al., 2018; Farabi et al., 2019), zeolite (Cheng et al., 2019), resin (Trombettoni et al., 2018; Ma et al., 2015), silica (Hasan et al., 2015) and several other metals including zirconia (Luo et al., 2017) and niobium (Celdeira et al., 2014). In addition, solid acid catalysts have more advantages compared to homogeneous alternatives, such as sulfuric acid. For instance, they do not cause corrosion, withstand high temperatures and pressures, are easily recycled, have a large surface area, and easily separate after the product is formed (Gebremariam \& Marchetti, 2018b).

Sulfonated carbon catalyst is used for the production of biodiesel from raw materials with high FFA content, such as palm oil distilled (Farabi et al., 2019; Sangar et al., 2019), and waste cooking oil (Vargas et al., 2019; Maneechakr et al., 2020; Nata et al., 2017). However, it has disadvantages, such as low density, which is difficult to disperse in batch reaction systems (Liu et al., 2010). The sulfonated carbon is applied to the supporting solids, such as silica, to show the excellent catalyst performance (Liu et al., 2010; Wilson \& Lee, 2012; Melero et., 2009).

Zeolite is one of the silica compounds that have the potential to be developed as a supporting part of sulfonated carbon. The selection of zeolite to be used as solid support catalyzes chemical reactions because its nature as an acidic solid has a porous crystal structure, large surface area, and good acidity value (Marchetti \& Errazu, 2008). Also, it is quite profitable due to its abundant amount and relatively low price, which reduces production costs.

The carbon source embedded in the zeolite solid must be soluble and absorbed on its surface. A cheap and sufficient carbon source is molasses with carbon in the form of dissolved sugars by $50-70 \%$. Therefore, it has the potential to produce strong carbon material. Besides, the disulfonated was carried out to produce stable solids with a large active site, which is referred to as sulfonated carbon (Liu et al., 2010). It is sourced from molasses embedded in zeolites and might be a catalyst material for FFA esterification. 
The purpose of this study was to examine the performance of zeolite-sulfonate carbon composite catalysts through esterification reactions with FFA from POME and methanol. The research used an experimental FFA esterification reaction from POME with CCD. This approach shortens the optimization time by reducing the combination variation of independent variables used. Some independent variables, such as temperature, catalyst weight, and reaction time, were used. The processing of response variables, such as FAME yield, acid number, and viscosity, used statistical methods, such as RSM, to obtain the relationship between these responses and the independent variables used in esterification. This method helps determine the optimum conditions due to the simultaneously changed variables used.

\section{MATERIALS AND METHODOLOGY}

\section{Materials}

The apparatus was used in this study include analytical balances, hot plates, centrifuges, sets of reflux tools, glass bikers, measuring cups, volume pipettes, drip pipettes, Erlenmeyer $250 \mathrm{~mL}$, burettes, boiling flasks, magnetic stirrers, pycnometers, viscometers, water baths, thermometers, split funnels, stopwatches. The materials were used in this study include palm oil waste, Sodium Hydroxide, Methanol p.a, Phenolphthalein Indicator, Akuades, Oxalic Acid, The natural zeolite $(\mathrm{Z})$ clinoptilolite with crystallographic unit cell $\mathrm{K}_{5.17} \mathrm{Mg}_{0.16}\left(\mathrm{Al}_{6} \mathrm{Si}_{30} \mathrm{O}_{72}\right) \cdot 24 \mathrm{H}_{2} \mathrm{O}$ (Suminta \& Las, 2018) obtained from Bayah, sulfuric acid, $\mathrm{HCl}$ and for the characterization catalyst we used FTIR, SEM, and the acidity analysis.

\section{Preparation of Sulfonated Carbon-zeolite Composite Catalyst}

The natural zeolite $(\mathrm{Z})$ clinoptilolite with crystallographic unit cell $\mathrm{K}_{5.17} \mathrm{Mg}_{0.16}\left(\mathrm{Al}_{6} \mathrm{Si}_{30} \mathrm{O}_{72}\right) \cdot 24 \mathrm{H}_{2} \mathrm{O}$ (Suminta \& Las, 2018) obtained from Bayah was used. It was pureed and sieved with a size of 200 mesh and soaked with 1.0 M sulfuric acid for two $h$, then washed with distilled water until it was neutral. Ten grams of pure natural zeolite, which has been smooth and clean, is dispersed into $100 \mathrm{~mL}$ of $30 \%$ molasses at $80^{\circ} \mathrm{C}$ while stirring to form a paste. The formed paste is roasted at $120^{\circ} \mathrm{C}$ to form caramel, then mashed and carbonated for 30 minutes at temperatures between $350^{\circ} \mathrm{C}$ with $\mathrm{N}_{2}$ gas. The carbonization results are referred to as Carbon-Zeolite (CZ) composites.

The resulting CZ composite added $50.0 \mathrm{~mL}$ of concentrated $\mathrm{H}_{2} \mathrm{SO}_{4}$ was refluxed at $175^{\circ} \mathrm{C}$ for $15 \mathrm{~h}$ and washed with $80^{\circ} \mathrm{C}$ demineralized water until the filtrate had a neutral $\mathrm{pH}$. The mixture was then centrifuged and dried at $120^{\circ} \mathrm{C}$ for $24 \mathrm{~h}$. The result is referred to as sulfonated carbon-zeolite (SCZ) composite catalysts and is characterized by the SEM, FTIR, and acidity properties of the catalyst. 


\section{The Characterization Catalyst with SEM}

SEM was used to determine the structure and shape of the catalyst surface, while to analyze the catalyst using SEM, the catalyst was dried using the oven at $110^{\circ} \mathrm{C}$ for 4 hours. Then the bentonite was mashed and sifted with a 200-mesh sieve. Finally, the SEM was operated at a voltage of $20 \mathrm{kV}$ (Meçabih, 2016).

\section{The Characterization Catalyst with FT-IR}

FT-IR spectrophotometers can analyze the functional groups contained in sulfonated carbon-zeolite composite catalysts with the working principle of vibration of their atoms. For analysis of spectrophotometer, FT-IR sulfonated carbon-zeolite composite catalyst as much as $1 \mathrm{mg}$ each and mixed with $100 \mathrm{mg} \mathrm{KBr}$ and then made pellets. Measurements were performed on wave numbers 400 to $4000 \mathrm{~cm}^{-1}$ using the Shimadzu FTIR 8201 infrared spectrophotometer (Ravindra et al., 2013).

\section{The Acidity Test of the Sulfonated Carbon-zeolite Composite Catalyst}

One gram of SCZ composite catalyst was immersed in $100 \mathrm{~mL} 0.5 \mathrm{~N} \mathrm{NaOH}$ for four $\mathrm{h}$ while stirring continuously. The mixture was filtered, and $5.0 \mathrm{~mL}$ was taken, and added phenolphthalein indicator before titrating with $0.5 \mathrm{~N} \mathrm{HCl}$. The amount of Arrhenius acid site as sulfonate in the catalyst was calculated from the $\mathrm{NaOH}$ reacting with the sulfonate group on SCZ. Calculation of the acidity test using the formula below:

Total acidity $=m_{\mathrm{NaOH}(a)}-m_{\mathrm{NaOH}(b)}$

Note:

$\mathrm{m}_{\mathrm{NaOH}(\mathrm{a})}$ : initial of $\mathrm{mol} \mathrm{NaOH}$

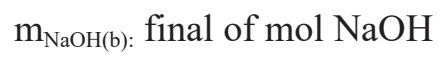

\section{FFA Esterification from POME}

The esterification reaction was carried out using a $250 \mathrm{~mL}$ boiling flask equipped with a reflux device. First, $25 \mathrm{~g}$ of oil from POME was added to $80 \mathrm{~mL}$ methanol, followed by an $\mathrm{SCZ}$ catalyst. The process was carried out based on three variables, including temperature, catalyst weight, and reaction time. Next, the resulting product in the form of FAME is separated from the catalyst and water formed by a separating funnel. Afterward, the FAME yield, acid number (by the AOCS Official Method Cd 3d-63), and kinematic viscosity at $40^{\circ} \mathrm{C}$ (by the ASTM D2270-10 method) were analyzed. 


\section{Experimental Design and Modeling}

The experimental design is carried out using the CCD. Three variables that influence the process of FFA esterification with methanol using a catalyst SCZ were observed, namely the temperature, the catalyst weight, and reaction time. The three-factor design is carried out at three levels and dimensionless coded with values -1 (lowest level), 0 (middle level), and +1 (highest level). The variable dimensionless code for temperature, catalyst weight, and reaction time, respectively $\mathrm{x}_{1}, \mathrm{x}_{2}$, and $\mathrm{x}_{3}$, make the same intervals of all variables, making the calculations easier. The second phase experiment with CCD design uses three independent variables, and the rotatability value is: $\left(3^{2}\right)^{1 / 4}=1.7$. Therefore, value \pm 1.7 includes the value used for coding. The encoding value of the independent variable is calculated using Equations 1-3:

$$
\begin{aligned}
& x_{1}=\frac{\eta_{1}-80^{\circ} \mathrm{C}}{10^{\circ} \mathrm{C}} \\
& x_{3}=\frac{\eta_{3}-2.0 \mathrm{~g}}{1.0 \mathrm{~g}} \\
& x_{2}=\frac{\eta_{2}-120 \mathrm{~min}}{30 \mathrm{~min}}
\end{aligned}
$$

Where $\eta_{1}, \eta_{2}$ and $\eta_{3}$ are the actual temperature values, catalyst weight, and reaction time variables. Based on the Equations 1-3, the coding values for the independent variables $\left(\mathrm{x}_{1}, \mathrm{x}_{2}\right.$ dan $\left.\mathrm{x}_{3}\right)$ are shown in Table 1. After coding, the experimental design using the CCD method is displayed in Table 2.

The experimental design was carried out with 20 run tests, as shown in Table 2. Afterward, each response variable, including FAME yield $\left(\mathrm{y}_{1}\right)$, acid number $\left(\mathrm{y}_{2}\right)$, and kinematic viscosity at $40^{\circ} \mathrm{C}\left(\mathrm{y}_{3}\right)$, were obtained. Finally, the optimization model was calculated using MATLAB R2018b in the form of a quadratic polynomial model to determine the interrelationship between the independent variables $\left(\mathrm{x}_{1}, \mathrm{x}_{2}\right.$, and $\left.\mathrm{x}_{3}\right)$ formulated in Equation 4.

$$
\hat{y}=\beta_{o}+\sum_{i=1}^{k} \hat{\beta}_{i} X_{i}+\sum_{i=1}^{k} \hat{\beta}_{i i} X_{i}^{2}+\sum_{i=1} \sum_{j=1} \hat{\beta}_{i j} X_{i} X_{j}, i>j
$$

Table 1

Variable values and codings

\begin{tabular}{lcccccc}
\hline \multicolumn{1}{c}{ Independent Variable } & Unit & \multicolumn{5}{c}{ Value } \\
\hline Coding & - & -1.7 & -1 & 0 & +1 & +1.7 \\
Temperature & ${ }^{\circ} \mathrm{C}$ & 63 & 70 & 80 & 90 & 97 \\
catalyst weight & $\mathrm{g}$ & 0.3 & 1.0 & 2.0 & 3.0 & 3.7 \\
Reaction time & minutes & 69 & 90 & 120 & 150 & 171 \\
\hline
\end{tabular}


Table 2

$C C D$ with three variables

\begin{tabular}{ccccccc}
\hline \multirow{2}{*}{ Run } & \multicolumn{2}{c}{ Temperature } & \multicolumn{2}{c}{ catalyst weight } & \multicolumn{2}{c}{ Reaction time } \\
\cline { 2 - 6 } & Actual $\left({ }^{\circ} \mathrm{C}\right)$ & Code $\left(\mathrm{x}_{1}\right)$ & Actual $(\mathrm{g})$ & Code $\left(\mathrm{x}_{2}\right)$ & Actual $($ minutes $)$ & Code $\left(\mathrm{x}_{3}\right)$ \\
\hline 1 & 90 & +1 & 3.0 & +1 & 150 & +1 \\
2 & 90 & +1 & 3.0 & +1 & 90 & -1 \\
3 & 90 & +1 & 1.0 & -1 & 150 & +1 \\
4 & 90 & +1 & 1.0 & -1 & 90 & -1 \\
5 & 70 & -1 & 3.0 & +1 & 150 & +1 \\
6 & 70 & -1 & 3.0 & +1 & 90 & -1 \\
7 & 70 & -1 & 1.0 & -1 & 150 & +1 \\
8 & 70 & -1 & 1.0 & -1 & 90 & -1 \\
9 & 97 & +1.7 & 2.0 & 0 & 120 & 0 \\
10 & 63 & -1.7 & 2.0 & 0 & 120 & 0 \\
11 & 80 & 0 & 3.7 & +1.7 & 120 & 0 \\
12 & 80 & 0 & 0.3 & -1.7 & 120 & 0 \\
13 & 80 & 0 & 1.0 & 0 & 171 & +1.7 \\
14 & 80 & 0 & 1.0 & 0 & 69 & -1.7 \\
15 & 80 & 0 & 1.0 & 0 & 120 & 0 \\
16 & 80 & 0 & 1.0 & 0 & 120 & 0 \\
17 & 80 & 0 & 1.0 & 0 & 120 & 0 \\
18 & 80 & 0 & 1.0 & 0 & 120 & 0 \\
19 & 80 & 0 & 1.0 & 0 & 0 & 0 \\
20 & 80 & 0 & 1.0 & 0 & & 0 \\
\hline
\end{tabular}

The estimation of calculated parameters is considered significant in case the p-value $<0.05$, using the $\mathrm{F}$ test. To determine the best reaction conditions leading to the maximum, minimum, or target value of the response variable (in the model), using the global optimization method of the continuous desirability function (Derringer \& Suich, 1980). It consists of three forms of functions, such as maximum, minimum, and target value. The desirability function for these three optimization goals is formulated in the following Equations 5-7.

$$
\begin{aligned}
& d_{r}^{\max }=\left\langle\begin{array}{c|c}
0 & \begin{array}{c}
\text { if }, f_{r}(x)<A \\
\text { if }, A \leq f_{r}(x) \leq B \\
\text { if }, f_{r}(x)>B
\end{array} \\
1 & d_{r}^{\min }= \\
\left(\frac{f_{r}(x)-B}{A-B}\right) & \begin{array}{c}
\text { if }, f_{r}(x)>B \\
\text { if }, A \leq f_{r}(x) \leq B \\
\text { if }, f_{r}(x)<B
\end{array}
\end{array}\right.
\end{aligned}
$$




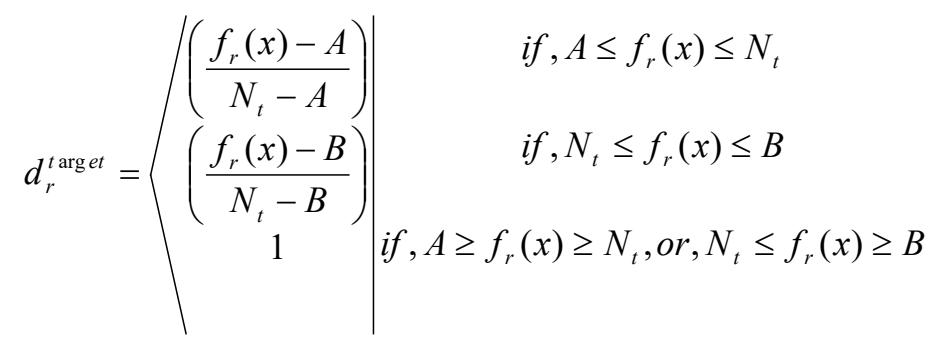

The value of $d_{r}^{\max }, d_{r}^{\max }$ and $d_{r}^{\text {target }}$ represents the individual desirability function of each $\mathrm{r}$ response arising from changes in independent variables $\mathrm{x}_{\mathrm{i}}$ by producing a response of $f_{r}(x)$. The global desirability $\left(D_{g}\right)$ might be determined through individual values using Equation 8 . The value $p$ in Equation 8 is the importance of the response tested. Each individual and global desirability has a scale from the most undesirable value of 0 (zero) to the most desirable (one).

$$
D_{g}=\left[d_{1}^{p_{1}} \cdot d_{2}^{p_{2}} \ldots . d_{n}^{p_{n}}\right]^{1 /\left(p_{1}+p_{2} \ldots+p_{n}\right)}
$$

\section{RESULT AND DISCUSSION}

\section{Catalyst Characterization}

The results of the catalyst surface topology Z, CZ, and SCZ using SEM are shown in Figure 1. The SEM image of $Z$ shows the granular surface structure if it is coated with carbon on the $\mathrm{CZ}$ composite. In the SEM images of $\mathrm{CZ}$ and SCZ, the $\mathrm{CZ}$ composites look smoother, and there are holes on the surface shown by the marked red square in Figure 1(b), which are pores of CZ. Furthermore, the SEM image of the SCZ composite shows that the surface shape of the SCZ composite catalyst has changed to become more trough because the structure of the carbon on the surface of the SCZ has been attached by sulfonate functional groups so that the fine structure of the $\mathrm{CZ}$ is lost this occurs because the surface of the SCZ catalyst is modified with some occasional cracks associated with partial oxidation, condensation and partial destruction of the porous structure during

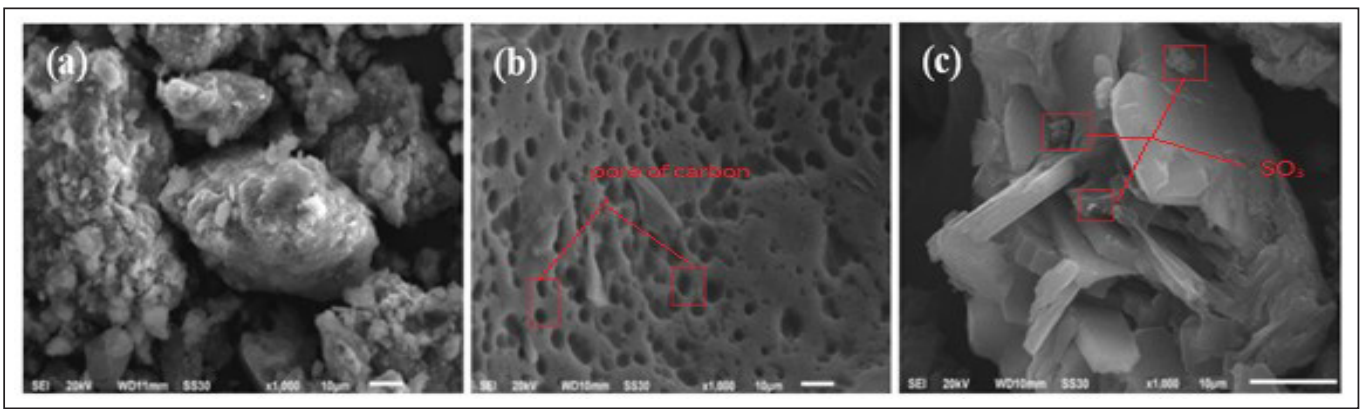

Figure 1. SEM image (a) Z, (b) $\mathrm{CZ}$ and (c) SCZ 
sulfonation, as reported by Lakhya et al. (2014). Transformation of backbone chemical properties, with a decrease in the number of aliphatic chains, an increase in aromatic rings, and the presence of oxidized groups, obtained after the sulfonation process resulted in a high density of functional groups, such as $\mathrm{SO}_{3} \mathrm{H}, \mathrm{COOH}$, and phenolic $\mathrm{OH}$ groups (Ngaosuwan et al., 2016). Predicted sulfonate atoms to be in Figure 1(c) inside a red square. Prediction of the existence of sulfonate atoms can be determined by comparing images of SEM SCZ results with the results of SEM SCAC (Sulfonate Carbon Active Catalyst) conducted by Ngawosuan et al. (2016).

SCZ identification was also carried out using the FT-IR spectrophotometer to determine the sulfonate functional groups attached to the $\mathrm{CZ}$ composite, and the analysis results are shown from the spectrum in Figure 2. According to Xu et al. (2010), the expected absorption of the $-\mathrm{SO}_{3} \mathrm{H}$ group was observed in the wave range of $1037-1200 \mathrm{~cm}^{-1}$; the result shows it was seen in the area of $1080.14 \mathrm{~cm}^{-1}$. The spectrum of the SCZ composite analysis before the sulfonation process contained peaks in the adjacent area of $1049.28 \mathrm{~cm}^{-1}$, which indicated the C-O vibrational region (Nata et al., 2017). It is due to carbon-based catalysts made through partially carbonized glucose, which form the polycyclic aromatic hydrocarbon compounds with many -OH groups. For this reason, no significant difference is seen in the spectrum before and after the sulfonation process in SCZ composites. The second spectrum of the analysis result shows a peak in the vibrational region of 1635.64

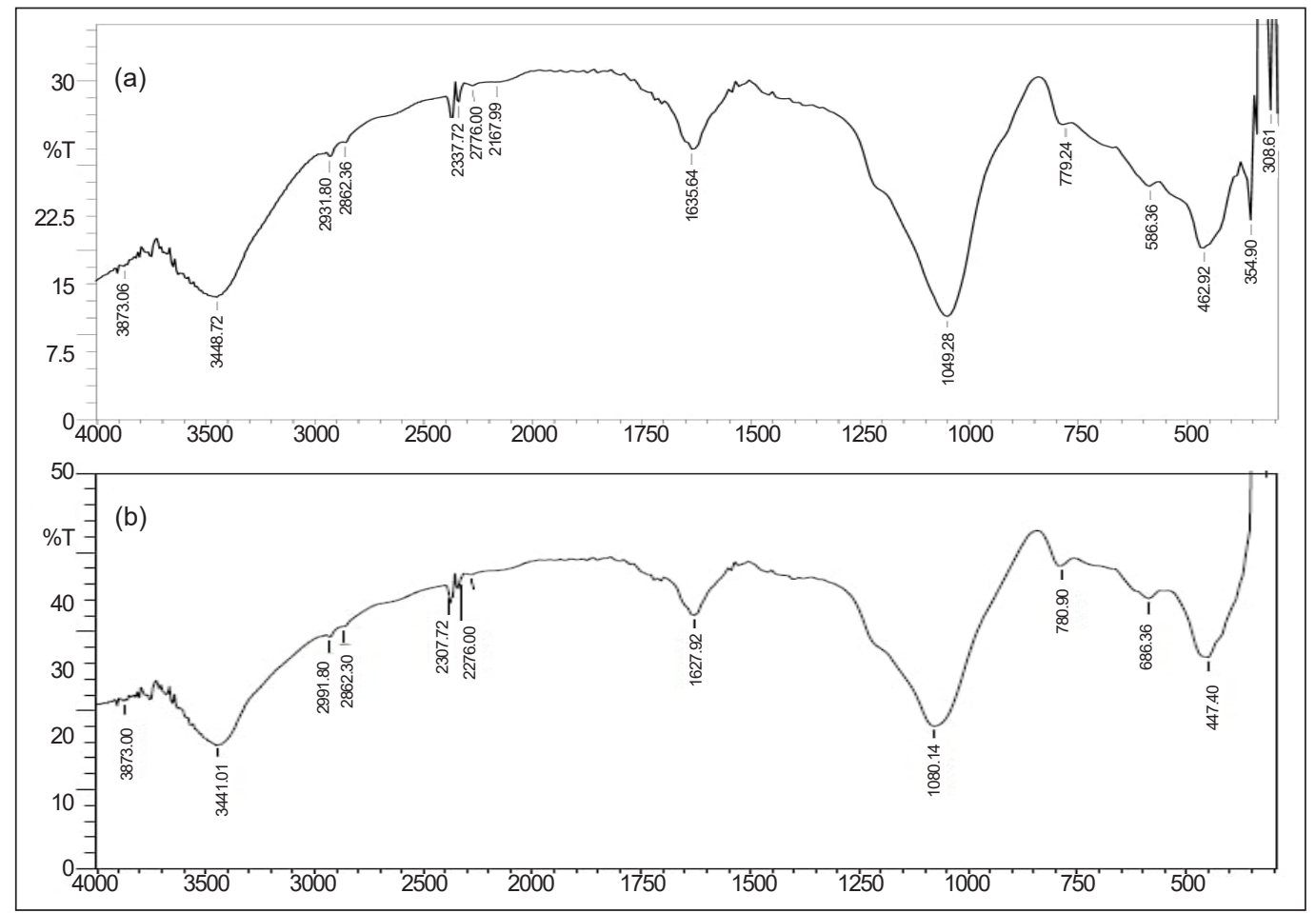

Figure 2. IR Spectrum (a) CZ dan (b) SCZ 
$\mathrm{cm}^{-1}$, which is estimated to be a $\mathrm{C}=\mathrm{C}$ aromatic region (Mar \& Somsook, 2012), and there is also a peak at $3441.72 \mathrm{~cm}-1$ which is expected for the -OH group. It is confirmed in the spectrum after the sulfonation process produces a peak at $3441.01 \mathrm{~cm}-1$, a specific area for free $\mathrm{OH}$. This result was also obtained in the study of Effiyanti et al. (2019).

The acidity test is carried out to determine how much the acidic sites indicate the number of sulfonate groups. It used the acid-base titration with $\mathrm{NaOH}$, which reacts with sulfonate groups on the catalyst, and the results are shown in Table 3 . The catalyst acidity of Z, CZ, and SCZ imply SCZ has a much higher acidity, $9.42 \mathrm{mmol} / \mathrm{g}$, compared to $\mathrm{Z}$ and $\mathrm{CZ}$ with 0.81 and $0.57 \mathrm{mmol} / \mathrm{g}$. It means there is an $\mathrm{H}^{+}$ion on the SCZ catalyst, which reacts with $\mathrm{NaOH}$ as the test base reactant. The acidity test results prove SCZ has a better active site than $\mathrm{Z}$ and $\mathrm{CZ}$, which is strengthened with FT-IR spectrum data. The $\mathrm{H}^{+}$ions bound to this sulfonate group are expected to act as the active site of the catalyst in the esterification process. It means the SCZ should be used in the next step for the optimization of the esterification

Table 3

The acidity test of sulfonated carbon-zeolite composite

\begin{tabular}{ccc}
\hline No. & Sample & Acidity $(\mathrm{mmol} / \mathrm{g})$ \\
\hline 1. & $\mathrm{Z}$ & 0.81 \\
2. & $\mathrm{ZC}$ & 0.57 \\
3. & ZSC & 9.42 \\
\hline
\end{tabular}
process.

\section{FAME Identification}

The methyl ester product formed from FFA esterification was identified using ${ }^{13} \mathrm{C}-\mathrm{NMR}$, as evidenced by the formation of the methoxy peak at a shift of 50-56 ppm. The results of the ${ }^{13} \mathrm{C}-\mathrm{NMR}$ analysis of FFA from POME and FAME products are shown in Figure 3. The ${ }^{13} \mathrm{C}$-NMR spectrum of FFA from POME not esterified shows the presence of carboxyl groups typical for FFA appearing peak at shift 180.31 ppm (Figure 3).

The FAME from the FFA esterification result was also identified by ${ }^{13} \mathrm{C}-\mathrm{NMR}$ spectroscopy and shown in Figure 3. The results obtained in accordance with research conducted by Traiq et al. (2011), shows there is a typical $\mathrm{C}=\mathrm{O}$ ester, and C-O signal at chemical shifts around $176 \mathrm{ppm}$ and $50.42 \mathrm{ppm}$ is slightly shifted from the results obtained by Tariq et al., where C carbonyl ester and C-O was identified at $174.26 \mathrm{ppm}$ and $51 \mathrm{ppm}$. Tariq et al. get the unsaturation in methyl esters indicated at the peaks around 131.88 and $127.08 \mathrm{ppm}$, and on this research, unsaturation in methyl esters indicated at the peaks around 130.08 and $127.92 \mathrm{ppm}$. Also, a chemical shift around $180.31 \mathrm{ppm}$ does not show the FAME, which indicates an esterification reaction occurs, and the carboxyl group from FFA changes into a FAME product. It is also characterized by the appearance of a C-methoxy signal, which is a typical carbon in the ester with a chemical shift of 51.45 ppm (Di Pietro et al., 2020). 


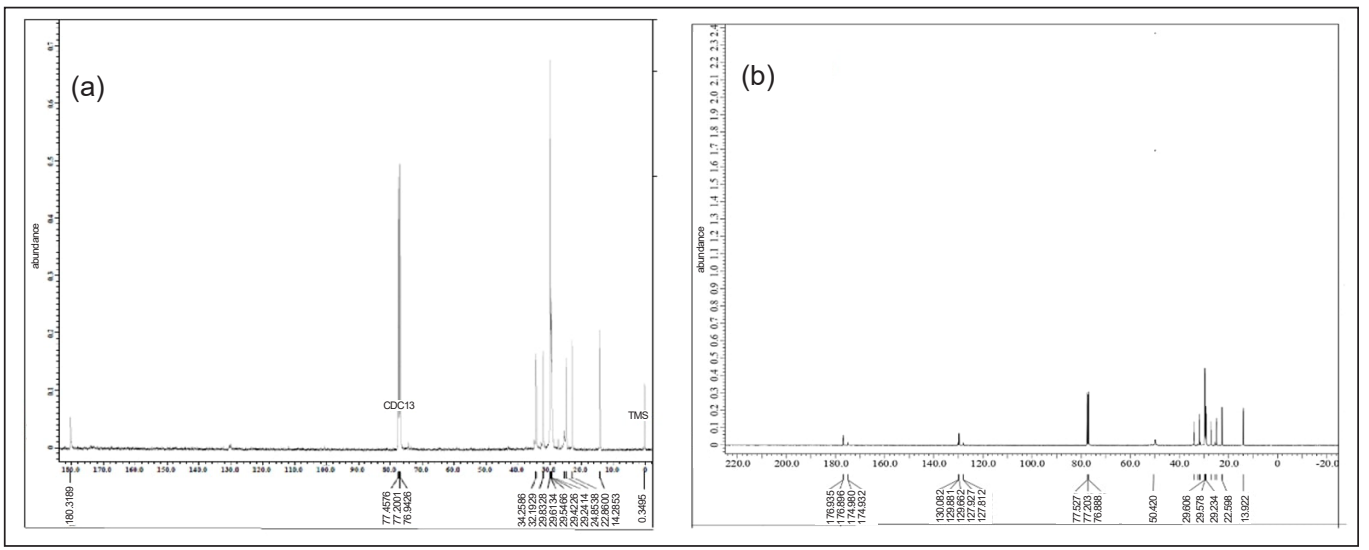

Figure 3. 13C-NMR of (a) POME and (b) FAME

\section{Optimization Process}

The process of esterifying free fatty acids in POME into methyl ester fatty acids using Composite Sulfonated Carbon Zeolite catalyst is influenced by temperature, reaction time, and weight catalyst. The reaction between the catalyst and FFA in POME with methanol assisted by composite sulfonated carbon zeolite catalyst to produce methyl ester fatty acids (FAME) can be seen in Figure 4. The protonation of the carbonyl group leads to the carbocation, and after the nucleophilic attack of the methanol molecule, a tetrahedral intermediate was generated, which formed the FAME. The catalyst has an active site that is atom hydrogen from $-\mathrm{SO}_{3} \mathrm{H}$. The hydrogen atom, as a Lewis acid, binds with the FFA, which then weakens the carbonyl bond and makes lower energy activation (Li et al., 2012).

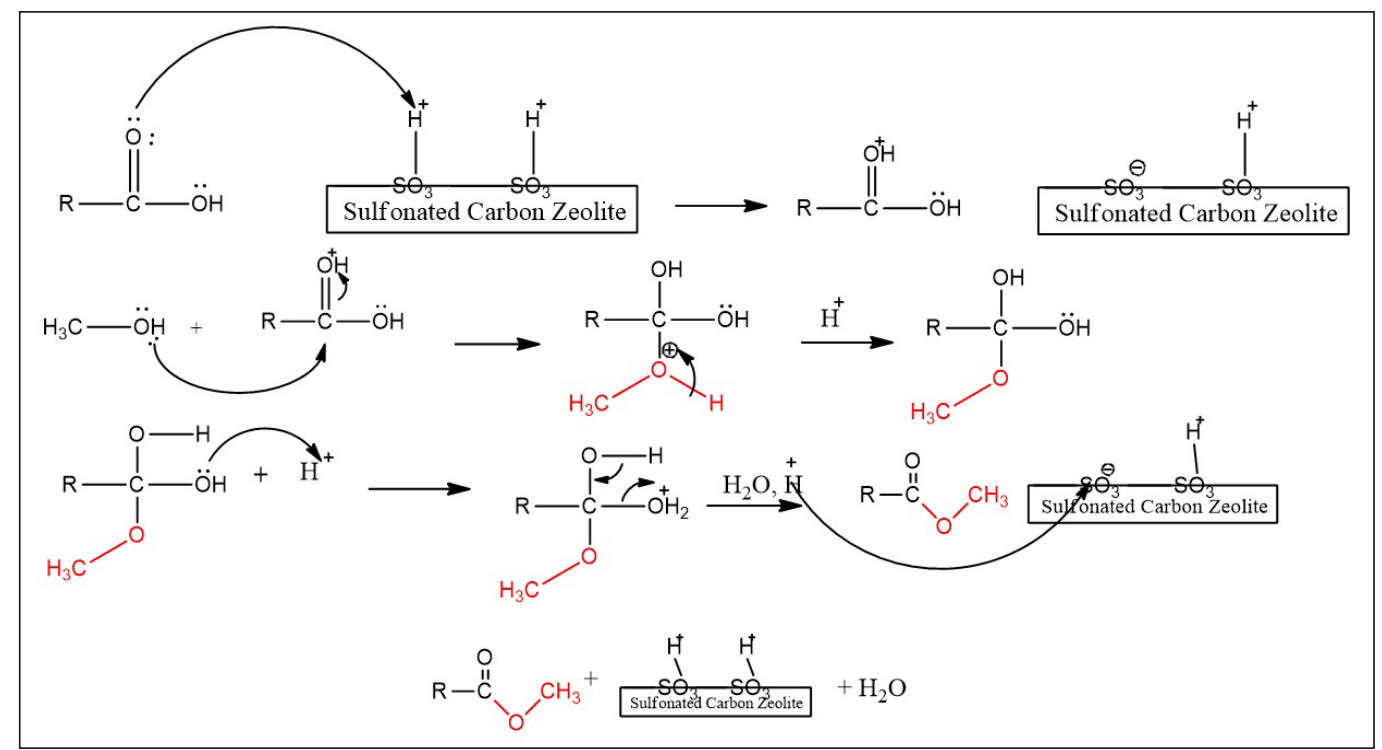

Figure 4. Mechanism of esterification FFA onto sulfonated carbon zeolite catalyst 
The FAME product produced from the FFA esterification with CCD for the three independent variables shows the effect on the FAME product. The processing of experimental data with MATLAB R2018b software produces a prediction model equation for the FAME yield response to the treatment of the independent variables of temperature, catalyst weight, and reaction time. The relationship of the three independent variables to the FAME yield response is shown in Figure 5, while the model formulation is in Equation 9.

$$
\begin{aligned}
& \mathrm{y}_{1}=89.64-0.46\left(\mathrm{x}_{1}\right)+7.63\left(\mathrm{x}_{2}\right)+2.20\left(\mathrm{x}_{3}\right)+0.66\left(\mathrm{x}_{1} \cdot \mathrm{x}_{2}\right)-1.50\left(\mathrm{x}_{1} \cdot \mathrm{x}_{3}\right)+0.78\left(\mathrm{x}_{2} \cdot \mathrm{x}_{3}\right)- \\
& 2.30\left(\mathrm{x}_{1}^{2}\right)-4.15\left(\mathrm{x}_{2}^{2}\right)-3.60\left(\mathrm{x}_{3}^{2}\right)
\end{aligned}
$$

An analysis of variance shows $F_{\text {count }}=10.16$, while $F_{\text {table }(9 ; 19 ; 0.05)}=2.42$. Since $F_{\text {count }}>$ $\mathrm{F}_{\text {table, }}$, the independent variables make a significant contribution to the model, which shows it affected the optimization model in Equation 9, and therefore, the predicted model should be accepted. Each independent variable affects the FAME yield response, which is shown in the mathematical model obtained.

Furthermore, the catalyst weight and reaction time positively affected the FAME attained. The temperature has a negative effect, but if it is combined with the catalyst weight and reaction time, it has a positive effect. The use of temperatures above the boiling point of the reactants, that is, methanol, in $64.5^{\circ} \mathrm{C}$ (Gafar, 2012), causes a decrease in FAME yield. The reactants changed to the gas phase, which reduces the reaction between reactants and fatty acids. The amount of FAME yield also increases with the addition of catalyst and reaction time. Nevertheless, the excess catalyst and long reaction time reduce the amount of the products due to the equilibrium and the change in variable conditions,

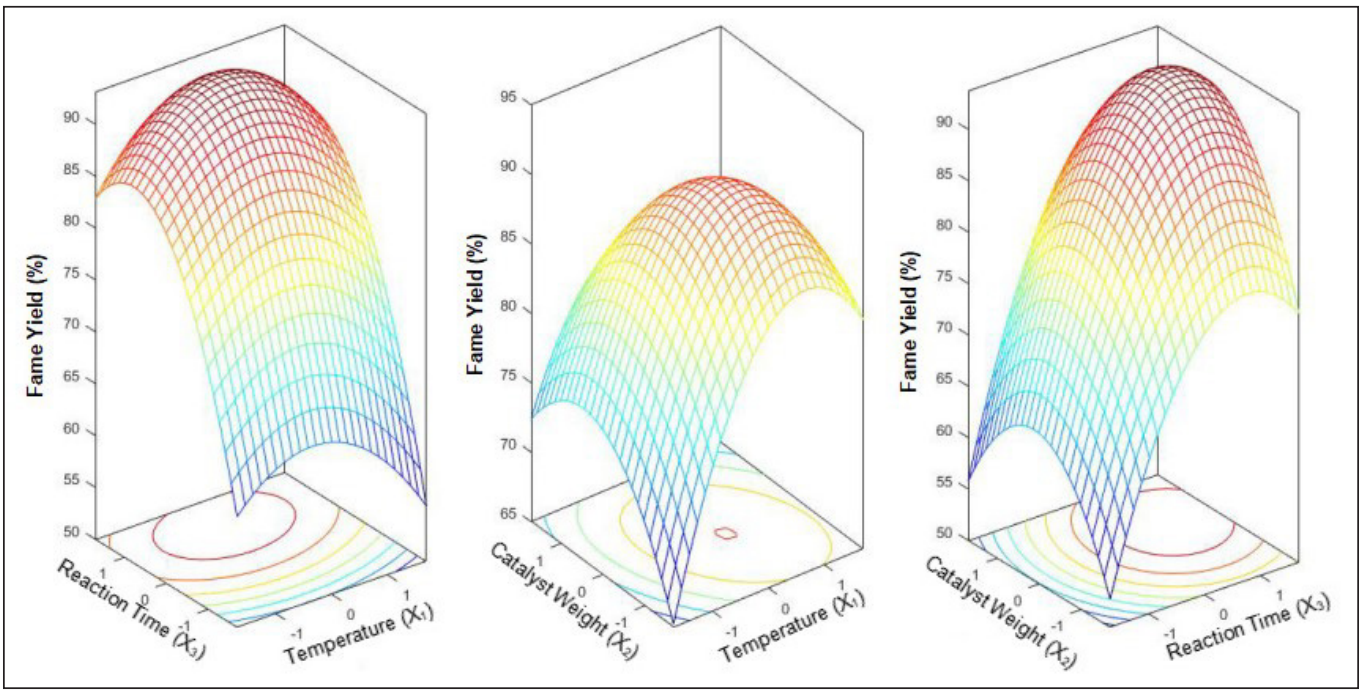

Figure 5. The relationship of the three independent variables to the FAME yield response 
which simultaneously causes the reaction to shift toward the reactants side. The optimum conditions for the FAME yield were obtained at a temperature of $79^{\circ} \mathrm{C}$, the catalyst weight of $3.00 \mathrm{~g}$, and a reaction time of 134 minutes with the FAME yield of $93.75 \%$. The weight of the catalyst used to get the optimum FAME result is $3.00 \mathrm{~g}$ of this result in accordance with the results obtained by Irawati et al. (2019), but the production of methyl ester that Irawati did use palm olein. The optimum temperature and reaction time obtained is close to the results obtained by William et al. (2016), which is $60^{\circ} \mathrm{C}$ for 3 hours made from distillate palm fatty acids. Optimization of esterification reactions shows that POME esterification reactions are catalyzed by SCZ catalysts at less high temperatures and a period of 120-150 minutes. It happens because the reaction that runs below or above the optimum point of the reaction of the collision theory between molecules will disappear caused by the reactants made less has been converted into products resulting in a small product yield marked by a decreased graph (Ofoefule et al., 2019).

The acid number analyzed the FAME products formed through titration. The smaller the acid number, the higher the quality of the FAME produced. In general, the acid number is the $\mathrm{KOH}(\mathrm{mg})$ weight needed to neutralize the FFA contained in one gram of the sample. Additionally, the analysis results with $\mathrm{CCD}$ and data processing using the MATLAB $2018 \mathrm{~b}$ software indicated the effect of the independent variables on the acid numbers, as shown in Figure 6. The optimum conditions were obtained at $79^{\circ} \mathrm{C}, 3.00 \mathrm{~g}$ of catalyst, and a reaction time of 134 minutes with acid number 11.66. The results of these observations indicate that there are similarities in the optimum conditions achieved in acid numbers and FAME yield calculations.

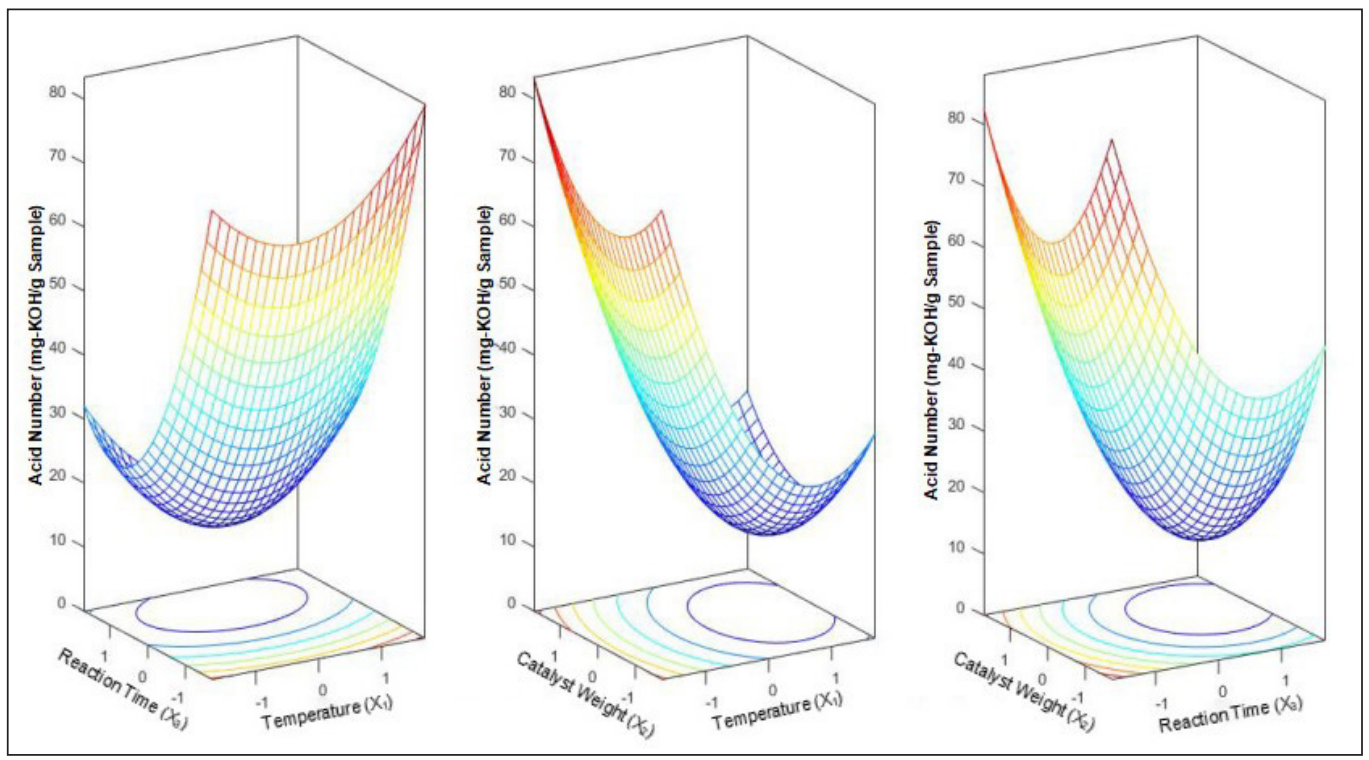

Figure 6. The relationship of the three independent variables to the acid number response 
ANOVA analysis results for the model given in Equation 10 show $\mathrm{F}_{\text {count }}=10.16$, while $F_{\text {table }(9 ; 19 ; 0.05)}=2.42$. Since $F_{\text {count }}>F_{\text {table }}$, the independent variable contributes significantly to the model, influencing the prediction model in Equation 10. Each independent variable affects the response of the acid number of the reaction results shown in the mathematical model obtained.

$$
\begin{aligned}
& \mathrm{y}_{2}=19.35+0.85\left(\mathrm{x}_{1}\right)-14.25\left(\mathrm{x}_{2}\right)-4.11\left(\mathrm{x}_{3}\right)-1.24\left(\mathrm{x}_{1} \cdot \mathrm{x}_{2}\right)+2.80\left(\mathrm{x}_{1} \cdot \mathrm{x}_{3}\right)-1.46\left(\mathrm{x}_{2} \cdot \mathrm{x}_{3}\right)+ \\
& 4.30\left(\mathrm{x}_{1}^{2}\right)+7.76\left(\mathrm{x}_{2}^{2}\right)+6.73\left(\mathrm{x}_{3}^{2}\right)
\end{aligned}
$$

The viscosity of the FAME produced also influences the quality of FAME as biodiesel fuel. Based on American Petroleum Institute (API), good quality biodiesel is biodiesel, which has a kinematic viscosity at $40^{\circ} \mathrm{C}$ in the range of values from 2.3 to $6.0 \mathrm{cSt}$, so optimization is set with the target value in the form of the middle value of viscosity, which is $4.15 \mathrm{cSt}$. Data was obtained from research with CCD to determine the effect of each process variable on the FAME viscosity response observed. The data processing results of the independent variables studied include temperature, catalyst weight, and reaction time for the FAME viscosity response shown in Figure 7 and the prediction model illustrated in Equation 11.

$$
\begin{aligned}
& \mathrm{y}_{3}=5.43-0.76\left(\mathrm{x}_{1}\right)-0.70\left(\mathrm{x}_{2}\right)-0.17\left(\mathrm{x}_{3}\right)-0.25\left(\mathrm{x}_{1} \cdot \mathrm{x}_{2}\right)-0.21\left(\mathrm{x}_{1} \cdot \mathrm{x}_{3}\right)-0.25\left(\mathrm{x}_{2} \cdot \mathrm{x}_{3}\right)-0.18\left(\mathrm{x}_{1}^{2}\right) \\
& -0.25\left(\mathrm{x}_{2}^{2}\right)-0.35\left(\mathrm{x}_{3}^{2}\right)
\end{aligned}
$$

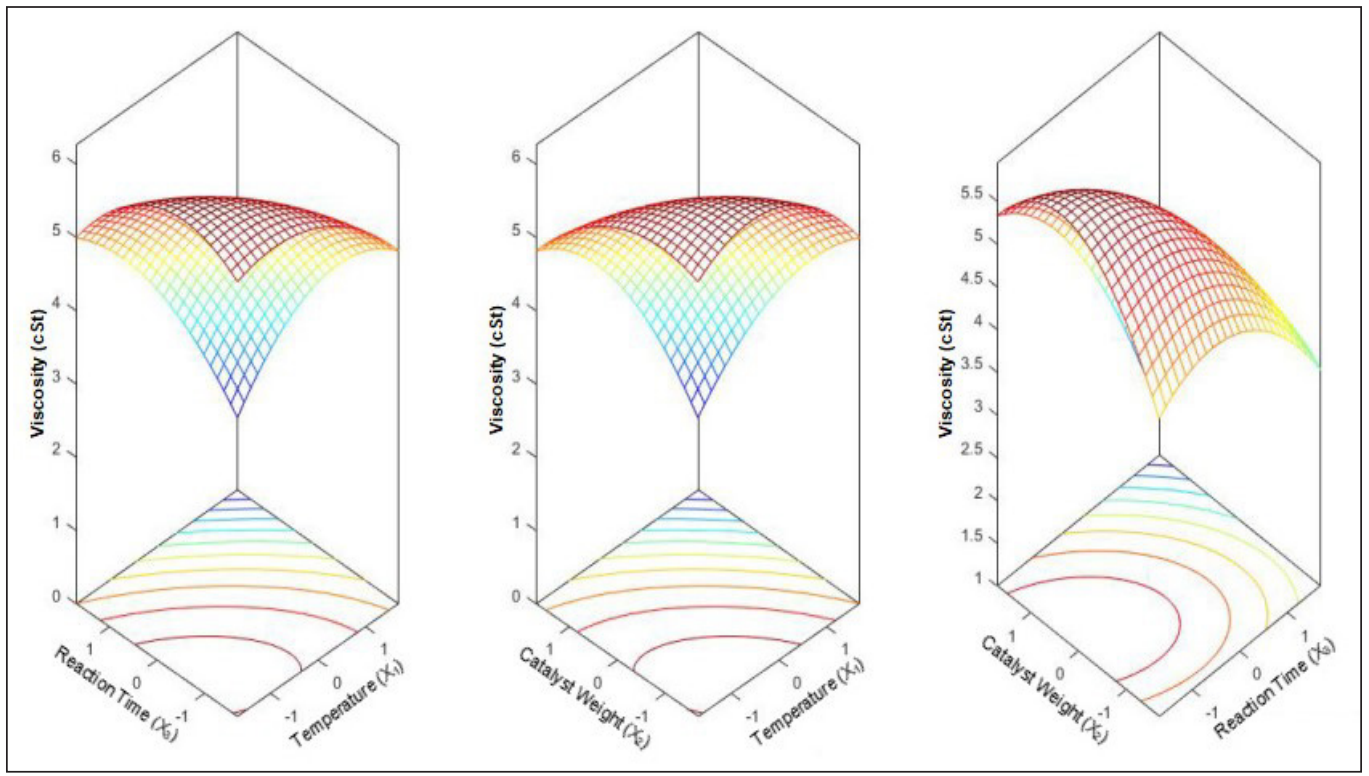

Figure 7. The relationship of the three independent variables to the FAME yield response 
The analysis of variance showed $F_{\text {count }}=18.12$, while $F_{\text {table }(9 ; 19 ; 0.05)}=2.42$. Since the $F_{\text {count }}>F_{\text {table, }}$, the independent variables significantly influence the model. It shows that the mathematical model obtained should be accepted in explaining the relationship of the independent variables with the FAME viscosity. The optimum conditions for the FAME viscosity include a temperature of $73^{\circ} \mathrm{C}$, a catalyst amount of $3.14 \mathrm{~g}$, and a reaction time of 123 minutes with the resulting FAME viscosity of $4.98 \mathrm{cSt}$.

\section{Validation of Prediction Model}

From the prediction models generated for the four response variables, it is possible to calculate the value of the response variable from each of the experimental conditions. The response obtained from the experimental results and the calculations using the Equations 9-11 are shown in Table 4. The data in Table 4 are then plotted to respond to the experimental results with the model for validation. It is meant to strengthen the mathematical model obtained.

Table 4

The result of response variables obtained experimentally and model

\begin{tabular}{ccccccc}
\hline Run & \multicolumn{2}{c}{ FAME Product $(\%)$} & \multicolumn{2}{c}{ Acid Number $(\mathrm{mg}-\mathrm{KOH} / \mathrm{g})$} & \multicolumn{2}{c}{ Viscosity $(\mathrm{cSt})$} \\
& Experiment & Model & Experiment & Model & Experiment & Model \\
\hline 1 & 88.02 & 88.89 & 22.37 & 20.73 & 2.39 & 2.32 \\
2 & 86.03 & 85.93 & 26.09 & 26.27 & 3.46 & 3.57 \\
3 & 70.29 & 70.75 & 55.49 & 54.63 & 4.66 & 4.71 \\
4 & 71.83 & 70.91 & 52.61 & 54.32 & 4.69 & 4.98 \\
5 & 90.05 & 91.48 & 18.58 & 15.90 & 4.99 & 4.77 \\
6 & 82.46 & 82.52 & 32.76 & 32.65 & 5.17 & 5.18 \\
7 & 75.37 & 75.99 & 46.01 & 44.85 & 6.21 & 6.16 \\
8 & 70.50 & 70.15 & 55.09 & 55.76 & 5.46 & 5.60 \\
9 & 82.14 & 82.20 & 33.36 & 33.23 & 3.83 & 3.61 \\
10 & 84.54 & 83.76 & 28.87 & 30.34 & 6.05 & 6.21 \\
11 & 91.68 & 90.60 & 15.54 & 17.54 & 3.38 & 3.53 \\
12 & 64.31 & 64.67 & 66.66 & 65.99 & 6.12 & 5.91 \\
13 & 84.71 & 82.97 & 28.56 & 31.81 & 3.93 & 4.15 \\
14 & 74.46 & 75.48 & 47.71 & 45.79 & 5.01 & 4.73 \\
15 & 89.96 & 89.64 & 18.75 & 19.35 & 5.41 & 5.44 \\
16 & 89.78 & 89.64 & 19.09 & 19.35 & 5.48 & 5.44 \\
17 & 89.47 & 89.64 & 19.67 & 19.35 & 5.43 & 5.44 \\
18 & 89.37 & 89.64 & 19.85 & 19.35 & 5.44 & 5.44 \\
19 & 89.53 & 89.64 & 19.55 & 19.35 & 5.39 & 5.44 \\
20 & 89.49 & 89.64 & 19.86 & 19.35 & 5.44 & 5.44 \\
\hline
\end{tabular}




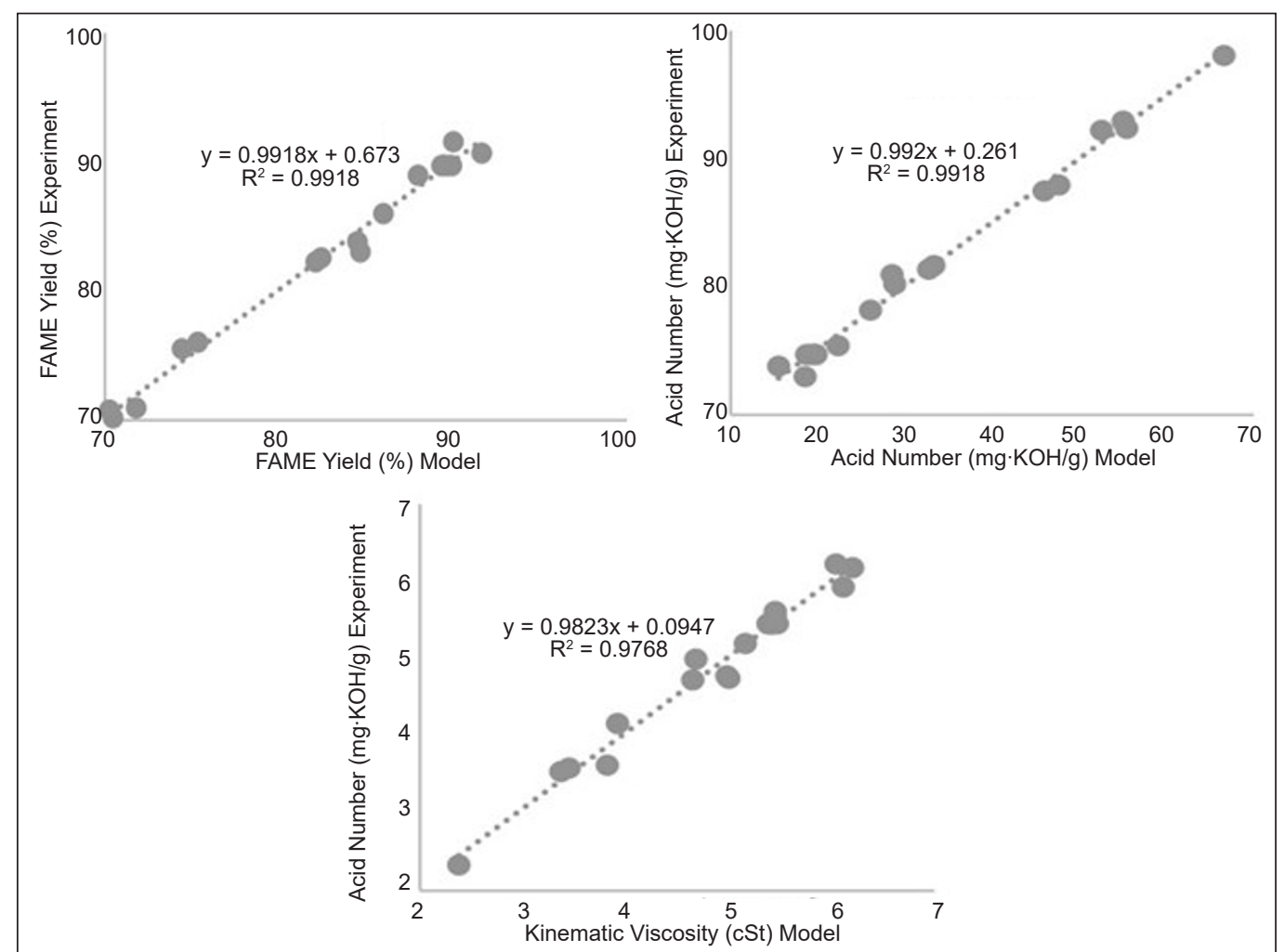

Figure 8. Plotting of response variables based on experimental data and models

Figure 8 shows the regression values for plotting each response variable from experimental data on the calculation of the FAME yield model, acid number, and viscosity, respectively $0.9918,0.9918$, and 0.9768 . The regression value obtained is close to 1 , and there is a match between the experimental and the model value. Therefore, the model validation results have the potential to predict the FAME yield, acid number, and kinematic viscosity, and the equation is declared useable to predict the response variable.

\section{The Optimum Conditions Selection using the Desirability Function}

The esterification process with temperature, catalyst weight, and reaction time were carried out simultaneously. The determination of the optimum point of FFA to FAME uses the desirability function since it is very compatible with the simultaneous optimization process (Derringer \& Suich, 1980). This method uses the maximum function (Equation 5), the target value (Equation 6), and the minimum value (Equation 7). The FAME product reacts as the maximum function, the acid number as the minimum function, and viscosity as the target value function responses. The desirability function for the four optimization objectives is each formulated in Equations 5-7. The results are shown in Table 5. 
Table 5

The optimum condition desirability test results based on the most desired priorities order

\begin{tabular}{lllll}
\hline Optimum condition & Response & Value & Individual desirability & Global desirability \\
\hline \multirow{2}{*}{ I } & FAME yield & 93.75 & 1 & \\
& Acid number & 11.66 & 1 & 0.985 \\
& Viscosity & 4.33 & 91.26 & \\
II & FAME yield & 92.52 & 94.80 & 0.967 \\
& Acid number & 13.96 & 94.80 & \\
\hline
\end{tabular}

The result of $D_{g}$ analysis using Equation 8 shows the optimum condition with the highest value is I with a $D_{g}$ of 0.98 . Furthermore, the ideal conditions for the FFA esterification process were carried out at $79^{\circ} \mathrm{C}, 3.00 \mathrm{~g}$ catalyst, and the reaction time 134 minutes. The esterification under these conditions produces a conversion of $93.75 \%$, the acid number, and the viscosity of $11.66 \mathrm{mg}-\mathrm{KOH} / \mathrm{g}$ and $4.98 \mathrm{cSt}$, respectively.

\section{CONCLUSION}

The research results on the manufacture of composite sulfonated carbon zeolite catalysts were successfully conducted, which is shown from the characterization of SCZ catalysts. The characterization of SEM catalyst composite sulfonated carbon zeolite indicates that sulfonated carbon has coated the surface of the zeolites, which is supported by the FT-IR characterization that indicates the presence of sulfonate groups at a wave count of 1080.14 $\mathrm{cm}^{-1}$. It is also reinforced by the results of calculating high acidity properties of $9.4 \mathrm{mmol}$ /g. Catalyst composite sulfonated carbon zeolite has been applied to the esterification of FFA in POME to produce FAME by using three free variables, namely temperature, weight catalyst, and reaction time and optimization. FFA esterification optimization with SCZ catalysts gets optimal conditions with a temperature of $79^{\circ} \mathrm{C}$, catalyst weight of $3.00 \mathrm{~g}$, and a reaction time of 134 minutes with FAME products of $93.75 \%$, given the properties below biodiesel viscosity required by API.

\section{ACKNOWLEDGMENT}

This work was supported by the Ministry of Research, Technology, and Higher Education of the Republic of Indonesia under the Consortium Research Grant of 2020.

\section{REFERENCES}

Aboelazayem, O., Gadalla, M., \& Saha, B. (2019). Derivatisation-free characterisation and supercritical conversion of free fatty acids into biodiesel from high acid value waste cooking oil. Renewable Energy, 143, 77-90. https://doi.org/10.1016/j.renene.2019.04.106. 
Borugadda, V. B., \& Goud, V. V. (2012). Biodiesel production from renewable feedstocks: Status and opportunities. Renewable and Sustainable Energy Reviews, 16(7), 4763-4784. https://doi.org/10.1016/j. rser.2012.04.010

Celdeira, P. A., Gonçalves, M., Figueiredo, F. C. A., Bosco, S. M. D., Mandelli, D., \& Carvalho, W. A. (2014). Sulfonated niobia and pillared clay as catalysts in etherification reaction of glycerol. Applied Catalysis A: General, 478, 98-106. https://doi.org/10.1016/j.apcata.2014.03.037

Cheng, J., Zhang, Z., Zhang, X., Liu, J., Zhou, J., \& Cen, K. (2019). Sulfonated mesoporous Y zeolite with nickel to catalyze hydrocracking of microalgae biodiesel into jet fuel range hydrocarbons. International Journal of Hydrogen Energy, 44(3), 1650-1658. https://doi.org/10.1016/j.ijhydene.2018.11.110

de Jesus, A. A., de Santana Souza, D. F., de Oliveira, J. A., de Deus, M. S., da Silva, M. G., Franceschi, E., da Silva Egues, S. M., \& Dariva, C. (2018). Mathematical modeling and experimental esterification at supercritical conditions for biodiesel production in a tubular reactor. Energy Conversion and Management, 171(April), 1697-1703. https://doi.org/10.1016/j.enconman.2018.06.108

Derringer, G., \& Suich, R. (1980). Simultaneous optimization of several response variables. Journal of Quality Technology, 12(4), 214-219. https://doi.org/10.1080/00224065.1980.11980968

Di Pietro, M. E., Mannu, A., \& Mele, A. (2020). NMR determination of free fatty acids in vegetable oils. Processes, 8(4), Article 410. https://doi.org/10.3390/pr8040410

Effiyanti, L., Susanto., Hikmah, N., Indrawan, D. A., \& Pari, G. (2019). Characterization and potential of wood waste sulfonated activated carbon catalyst based on rice husk hydrolysis reaction using microwave. Journal of Research Result Forest, 37(2), 67-80.

Encinar, J. M., Sánchez, N., Martínez, G., \& García, L. (2011). Study of biodiesel production from animal fats with high free fatty acid content. Bioresource Technology, 102(23), 10907-10914. https://doi.org/10.1016/j. biortech.2011.09.068

Farabi, M. S. A., Ibrahim, M. L., Rashid, U., \& Taufiq-Yap, Y. H. (2019). Esterification of palm fatty acid distillate using sulfonated carbon-based catalyst derived from palm kernel shell and bamboo. Energy Conversion and Management, 181(December 2018), 562-570. https://doi.org/10.1016/j.enconman.2018.12.033.

Gafar, A. (2012). Síntesis and biodiesel quality test from palm oil plant liquid waste transesterification process. Journal of Chemical Progress science, 2(1), 11-20.

Gebremariam, S. N., \& Marchetti, J. M. (2018a). Biodiesel production through sulfuric acid catalyzed transesterification of acidic oil: Techno economic feasibility of different process alternatives. Energy Conversion and Management, 174(August), 639-648. https://doi.org/10.1016/j.enconman.2018.08.078

Gebremariam, S. N., \& Marchetti, J. M. (2018b). Economics of biodiesel production: Review. Energy Conversion and Management, 168(February), 74-84. https://doi.org/10.1016/j.enconman.2018.05.002

Hasanudin., Said, M., Faizal, M., Dahlan, M. H., \& Wijaya, K. (2012). Hydrocracking of oil residue from palm oil mill effluent to biofuel. Sustainable Enviroment Research, 22(6), 395-400.

Hasan, Z., Yoon, J. W., \& Jhung, S. H. (2015). Esterification and acetylation reactions over in situ synthesized mesoporous sulfonated silica. Chemical Engineering Journal, 278, 105-112. https://doi.org/10.1016/j. cej.2014.12.025 
Irawati., Kurniawan, C., \& Harjono. (2019). Optimization of epoxidation fatty acid methyl esters (FAME) Based on palm olein as a cat filter additive. Indonesian Journal of Chemical Science, 8(1), 34-40.

Lathiya, D. R., Bhatt, D. V., \& Maheria, K. C. (2018). Synthesis of sulfonated carbon catalyst from waste orange peel for cost effective biodiesel production. Bioresource Technology Reports, 2(2017), 69-76. https://doi.org/10.1016/j.biteb.2018.04.007

Lakhya, J. K., Boro, J., \& Deka, D. (2014). Review on latest developments in biodiesel production using carbon-based catalysts. Renewable and Sustainable Energy Reviews, 29, 546-564. https://doi.org/10.1016/j. rser.2013.09.003

Li, J., Fu, Y. J., Qu, X. J., Wang, W., Luo, M., Zhao, C. J., \& Zu, Y. G. (2012). Biodiesel production from yellow horn (Xanthoceras sorbifolia Bunge.) seed oil using ion exchange resin as heterogeneous catalyst. Bioresource Technology, 108,112-118. https://doi.org/10.1016/j.biortech.2011.12.129

Liu, X. Y., Huang, M., Ma, H. L., Zhang, Z. Q., Gao, J. M., Zhu, Y. L., Han, X. J., \& Guo, X. Y. (2010). Preparation of a carbon-based solid acid catalyst by sulfonating activated carbon in a chemical reduction process. Molecules, 15(10), 7188-7196. https://doi.org/10.3390/molecules15107188

Luo, Y., Mei, Z., Liu, N., Wang, H., Han, C., \& He, S. (2017). Synthesis of mesoporous sulfated zirconia nanoparticles with high surface area and their applies for biodiesel production as effective catalysts. Catalysis Today, 298(November 2016), 99-108. https://doi.org/10.1016/j.cattod.2017.05.047

Ma, L., Han, Y., Sun, K., Lu, J., \& Ding, J. (2015). Optimization of acidified oil esterification catalyzed by sulfonated cation exchange resin using response surface methodology. Energy Conversion and Management, 98, 46-53. https://doi.org/10.1016/j.enconman.2015.03.092

Maneechakr, P., Samerjit, J., Uppakarnrod, S., \& Karnjanakom, S. (2020). Retraction notice to "Experimental design and kinetic study of ultrasonic assisted transesterification of waste cooking oil over sulfonated carbon catalyst derived from cyclodextrin"'[Journal of Industrial and Engineering Chemistry 32 (2015) 128 - 136]. Journal of Industrial and Engineering Chemistry, 87, 264-264. https://doi.org/10.1016/j. jiec.2020.03.031.

Mar, W. W., \& Samsook, E. (2012). Sulfonic-functionalized carbon catalyst for esterification of high free fatty acid. Procedia Engineering, 32, 212-218. https://doi.org/10.1016/j.proeng.2012.01.1259

Marchetti, J. M., \& Errazu, A. F. (2008). Comparison of different heterogeneous catalysts and different alcohols for the esterification reaction of oleic acid. Fuel, 87(15-16), 3477-3480. https://doi.org/10.1016/j. fuel.2008.05.011

Marchetti, J. M., Miguel, V. U., \& Errazu, A. F. (2008). Techno-economic study of different alternatives for biodiesel production. Fuel Processing Technology, 89(8), 740-748. https://doi.org/10.1016/j. fuproc.2008.01.007

Mardhiah, H. H., Ong, H. C., Masjuki, H. H., Lim, S., \& Pang, Y. L. (2017). Investigation of carbon-based solid acid catalyst from Jatropha curcas biomass in biodiesel production. Energy Conversion and Management, 144, 10-17. https://doi.org/10.1016/j.enconman.2017.04.038

Meçabih, Z. (2016). Characterization of pillared clay by SEM-EDX. Journal of Multidisciplinary Engineering Science and Technology, 3(6), 5107-5109. 
Melero, J. A., Iglesias, J., \& Morales, G. (2009). Heterogeneous acid catalysts for biodiesel production: Current status and future challenges. Green Chemistry, 11(9), 1285-1308. https://doi.org/10.1039/b902086a

Nata, I. F., Putra, M. D., Irawan, C., \& Lee, C. K. (2017). Catalytic performance of sulfonated carbon-based solid acid catalyst on esterification of waste cooking oil for biodiesel production. Journal of Environmental Chemical Engineering, 5(3), 2171-2175. https://doi.org/10.1016/j.jece.2017.04.029.

Ngawosuan, K., Jr Goodwin, J. G., \& Prasertdha, P. (2016). A green sulfonated carbon-based catalyst derived from coffee residue for esterification. Renewable Energy, 86, 262-269. https://doi.org/10.1016/j. renene. 2015.08 .010

Ofoefule, A. U., Esonye, C., Onukwuli, O. D., Nwaeze, E., \& Ume, C. S. (2019). Modeling and optimization of African pear seed oil esterification and transesterification using artificial neural network and response surface methodology comparative analysis. Industrial Crops and Products, 140, Article 111707. https:// doi.org/10.1016/j.indcrop.2019.111707

Ravindra, R. T., Kaneko, S., Endo, T., \& Lakhsmi, R. S. (2013). Spectroscopic characterization of bentonit. Journal of Laser, Optics \& Photonics, 4(3), 1-4.

Sangar, S. K., Lan, C. S., Razali, S. M., Farabi, M. S. A., \& Taufiq-Yap, Y. H. (2019). Methyl ester production from palm fatty acid distillate (PFAD) using sulfonated cow dung-derived carbon-based solid acid catalyst. Energy Conversion and Management, 196, 1306-1315. https://doi.org/10.1016/j.enconman.2019.06.073

Suminta, S., \& Las, T. (2018). Smoothing of mordenite crystal cage structure and natural klinoptilolite by rietveld method. Indonesian Journal of Material Science, 7(2), 73-78. https://doi.org/10.17146/ jsmi.2006.7.2.5004S

Tariq, M., Ali, S., Ahmad, F., Ahmad, M., Zafar, M., Khalid, N., \& Khan, M. A. (2011). Identification, FT-IR, NMR $\left({ }^{1} \mathrm{H}\right.$ and $\left.{ }^{13} \mathrm{C}\right)$ and $\mathrm{GC} / \mathrm{MS}$ studies of fatty acid methyl esters in biodiesel from rocket seed oil. Fuel Processing Technology, 92, 336-341. https://doi.org/10.1016/j.fuproc.2010.09.025

Trombettoni, V., Lanari, D., Prinsen, P., Luque, R., Marrocchi, A., \& Vaccaro, L. (2018). Recent advances in sulfonated resin catalysts for efficient biodiesel and bio-derived additives production. Progress in Energy and Combustion Science, 65, 136-162. https://doi.org/10.1016/j.pecs.2017.11.001

Vargas, E. M., Neves, M. C., Tarelho, L. A. C., \& Nunes, M. I. (2019). Solid catalysts obtained from wastes for FAME production using mixtures of refined palm oil and waste cooking oils. Renewable Energy, 136, 873-883. https://doi.org/10.1016/j.renene.2019.01.048

William., Sanjaya, J., Taslim., Herawan, T., \& Rivani, M. (2016). Optimization of biodiesel manufacturing process from distillate palm fatty acids (ALSD) and dimethyl carbonate (DMC) using Novozymes 435 catalyst. Journal Chemical Enggeenering USU, 5(1), 13-19. https://doi.org/10.32734/jtk.v5i1.1519

Wilson, K., \& Lee, A. F. (2012). Rational design of heterogeneous catalysts for biodiesel synthesis. Catalysis Science and Technology, 2(5), 884-897. https://doi.org/10.1039/c2cy20038d

Xu, B., Ren, J., Liu, X., Guo, Y., Gou, Y., Lu, G., \& Wang, Y. (2010). Novel sulfonated carbonaceous materials from $p$-toluenesulfonic acid/glucose as a high-performance solid-acid catalyst. Catalysis Communication, 11, 629-632. https://doi.org/10.1016/j.catcom.2010.01.010 
